\title{
3 Besearchs buare \\ High Burden of Anemia Among Pregnant Women in Tanzania: A Call to Address Its Determinants
}

\section{Bruno F. Sunguya}

Muhimbili University of Health and Allied Sciences School of Public Health and Social Sciences

Yue Ge

Fudan University School of Public Health

\section{Linda Mlunde}

Muhimbili University of Health and Allied Sciences School of Public Health and Social Sciences

\section{Rose Mpembeni}

Muhimbili University of Health and Allied Sciences School of Public Health and Social Sciences

\section{Germana Leyna}

Tanzania Food and Nutrition Centre

Jiayang Huang ( $\sim$ jiayanhuang@fudan.edu.cn )

School of Public Health, Fudan University Shanghai, China https://orcid.org/0000-0003-4166-6119

\section{Research}

Keywords: Anemia, pregnancy, Demographic and Health Survey, Tanzania, women of reproductive age

Posted Date: March 17th, 2021

DOl: https://doi.org/10.21203/rs.3.rs-307049/v1

License: (c) (1) This work is licensed under a Creative Commons Attribution 4.0 International License. Read Full License

Version of Record: A version of this preprint was published at Nutrition Journal on July 8th, 2021. See the published version at https://doi.org/10.1186/s12937-021-00726-0. 


\section{Abstract}

Background: Anemia in pregnancy is behind a significant burden of maternal mortality and poor birth outcomes globally. Efforts to address it need evidence on trends and its pertinent factors as they vary from one area to another.

Methods: We analyzed data of 23,203 women of reproductive age whose hemoglobin levels were measured from two Tanzania Demographic and Health Surveys (TDHS). Of them, 2,194 women were pregnant. Analyses employed descriptive analyses to determine the burden of anemia, its characteristics, and severity; GIS mapping to determine the regional changes of anemia between 2005 and 2015; and logistic regression to determine the remaining determinants of anemia among pregnant women using Stata 15.

Results: The burden of anemia among pregnant women in Tanzania has remained unprecedently high, and vary between regions. Despite such variation, there was no significant decline of anemia in general between the two periods [AOR $=0.964, p=0.747$ ). Anemia is currently prevalent in $57 \%$ of pregnant women in Tanzania. The burden is more likely to be higher among women aged 15-19 years than those aged between 20-34 years. It is more likely to be prevalent among those within large families, with no formal education, food insecurity, lack of health insurance, had no antimalaria during pregnancy, and had low frequency of ANC attendance. On the other hand, delivery in a health facility was protective against anemia.

Conclusions: Anemia in pregnancy remained persistently high and prevalent among $57 \%$ of pregnant women in Tanzania. Efforts to address anemia is crucial and need to be focused in regions with increasing burden of anemia among pregnant women. It is imperative to address important risk factors such as food insecurity, strengthening universal health coverage, empowering women of reproductive age with education and especially nutritional knowledge and advocating for early antenatal booking, attendance, and facility delivery.

\section{Background}

Globally, about one in three women of reproductive age (WRA) is estimated to suffer from anemia, presenting with haemoglobin $(\mathrm{Hb})$ below $11 \mathrm{~g} / \mathrm{dl}(25)$. The burden is even higher among pregnant women. The 2011 Nutrition Impact Model Study projected anemia to be prevalent among 38\% of pregnant women globally (13). Like other forms of chronic malnutrition, such unprecedented burden remains higher in lowand middle-income countries compared to developed nations. Within the Sub-Saharan Africa, anemia among pregnant women is the highest in West Africa, with the prevalence of $56 \%$ (25). Anemia during pregnancy is associated with a number of adverse events for both the mother and her offspring $(12,21)$. Chiefly, it has been an important cause of maternal and perinatal mortality globally $(1,22)$. Severity of the adverse outcomes of anemia in pregnancy depends largely on severity of anemia itself (22). Some of the outcomes include premature labor and rupture of membranes (4), pregnancy induced hypertensive 
diseases including eclampsia and pre-eclampsia $(16,26)$, risk of caesarean sections, and poor child outcomes including low birth weight, small for gestation age, still birth, and neonatal deaths (4). Anemia in pregnancy may also predispose a child to early developmental challenges (3) and subsequent early burden of undernutrition (6).

Like in other low and middle-income countries, anemia remains one of the important indirect causes of $14.5 \%$ of maternal deaths in Tanzania (2). Despite efforts in place to address persistent maternal deaths in the country, results have not been promising, calling for further efforts in mitigating the important determinants such as anemia (27). Currently, maternal mortality rate stands at 576 deaths per 100,000 live births (27). This burden can be attributed by a number of direct and indirect causes including unprecedented burden of anemia in pre-pregnancy and the pregnancy period (7). Like other forms of anemia in the country, among pregnant women anemia in Tanzania is chiefly of nutrition in nature (8, 20). Other forms that contribute to such burden include diseases such as malaria, parasitic worms which are also preventable (10).

Interventions to address anemia have resulted into a small but notable decline of prevalence of anemia among vulnerable populations in Tanzania. For example, it has declined among children under the age of five years old from $71 \%$ in 2005 to $59 \%$ in 2015 in Tanzania (24). Similarly, anemia has significantly declined among women of reproductive age 48\% in 2005 to 45\% in 2015 (27). However, lack of similar analyses in Tanzania among pregnant women who carry significant risks needed to be addressed and therefore a rationale of this study.

Like for other sub-populations in Tanzania (24), determinants of anemia among pregnant women may also vary from one region to another. Efforts to address this burden therefore need tailored approach and targeted interventions. Such evidence is not available to effect policy and guidelines in the country. Variation of magnitudes and determinants were found in our previous publications among women and children $(24,29)$. In addressing these scientific gaps, this study therefore aimed to first determine the magnitude of anemia among pregnant women in Tanzania and changes of this burden in a period of 10 years. Second, to determine the regional differences and changes over time between regions. Third, to characterize anemia in pregnancy in order to understand the vulnerabilities among pregnant women and to examine the determinants of anemia in pregnancy for policy and implementation recommendations in Tanzania.

\section{Methods}

This was a secondary data analyses that utilized the nationally representative samples of the Tanzania Demographic and Health Surveys (TDHS) of 2004-2005 (28) and the most latest survey of 2015-2016 (27). The authors chose these datasets owing to the availability of anemia data that was introduced to DHS program in 2004-2005 for Tanzania. DHS datasets are generated from cross-sectional studies conducted in all regions. For Tanzania, it includes data from the mainland and Zanzibar islands. The National Bureau of Statistics (NBS) has been the leading institution in the mainland, while Zanzibar 
Bureau of Statistics (ZBS) has been leading these studies in the isles through the USAID funding and technical leadership of MEASURES (https://dhsprogram.com/). Since 1992, DHS surveys have been vital sources for nationally representative data on maternal, child, and household's characteristics related to health, wellbeing, health services delivery, and other social determinants of health in Tanzania.

Specifically, for nutrition research, data is collected from children and women on their anthropometric measurements and therefore generating nutrition status variables, biological markers for micronutrients such as iron, vitamin A, and iodine, that can help generate burdens of anemia, vitamin A deficiency, and iodine deficiency in general population and sub-populations such as vulnerable populations like women of reproductive age and pregnant women.

This analysis aimed to examine the burden of anemia among pregnant women during the respective surveys. It therefore analyzed data of a total of 23,203 women of reproductive age whose hemoglobin levels were measured, and out of them, a sub-population of 2,194 women who were pregnant during the respective surveys analyzed further. The distribution of this population was as follows: for the 2004 survey, a total of 10,139 were analyzed of which 1,075 were pregnant at the time of survey; and in 20152016 survey, a total of 13,064 women of reproductive age were included of which, 1,119 confirmed to be pregnant at the time of the survey.

In both surveys, the main outcome variable was anemia defined as a blood haemoglobin $(\mathrm{Hb})$ level below $11.0 \mathrm{~g} / \mathrm{dl}$ in pregnant women and below $12.0 \mathrm{~g} / \mathrm{dl}$ in non-pregnant women. Blood samples were drawn and analyses conducted according to the standard procedures The cutoffs are adjusted for altitude for enumeration areas above 1,000 meters and cigarette smoking (13). Independent variables included demographic, household, and other maternal and child characteristics based on previous literatures.

Further within the independent variables, the individual characteristics included age (in years); highest education level attained; current marital status, use of any form of tobacco; and having any form of health insurance. Other variables under households' characteristics included place of residence weather was in urban or rural, number of household's members, household's food security, and weighted wealth index. Like in our previous studies $(24,29)$, weighted wealth index was computed using principal component analysis and factor analyses of the household assets ownership. The factor loadings which are sample weights are summed to generate the weighted wealth index. DHS data presents the quintiles of such weighted wealth index categories as poorest, poorer, middle, richer, and richest. Reproductive and child characteristics included number of children ever born, age at the first child birth, gestation age at first antenatal booking, number of antenatal clinic visit, provision and use of folic acid and iron tablets during pregnancy, place of delivery, and deworming during the last pregnancy.

Data was analyzed using descriptive statistics, regression analyses, and using GIS mapping to indicate the changes within regions as far as anemia in pregnancy is concerned. For descriptive analyses, Pearson's Chi-square test was used to examine the differences in the severity of anemia in pregnancy between the survey periods, i.e. 2004-2005 and 2015-2016. Similar statistical method was used to determine differences of anemia with regards demographic, household, and other health-related 
characteristics that are hypothesized to be related to anemia among pregnant women. Further, the regional differences in the burden of anemia among pregnant women were examined over the period of ten years and color-coded to show the magnitude of change between the regions.

To examine independent change of anemia among pregnant women in Tanzania and the remaining determinants of anemia among pregnant women in Tanzania, the 2004-2005 and 2015-2016 datasets were analyzed using multiple logistic regression analysis. Such analysis was conducted to determine the change of the burden of anemia among pregnant women after adjusting for including demographic, households' and health-related characteristics, to determine the adjusted decline. Finally, multiple logistic regression analysis was conducted to determine the remaining contributing factors. This could be achieved through multiple logistic regression analysis that involved the outcome variable as anemia among WRA and independent variables, including socio-demographic, household, and health-related characteristics using the TDHS 2015-2016. Data were analyzed using Stata version 15 software. Since this was a secondary analysis of DHS data, we did not require a separate ethical approval. The primary data collection had followed and adhered to all ethical considerations including informed consent and permission to use the data was sought through the DHS website (https://dhsprogram.com/).

\section{Results}

\section{The burden of Anemia in pregnancy between 2005 and 2015}

The burden of anemia remains high among women of reproductive age despite a slight decline from $48.4 \%$ in 2004 to $44.8 \%$ ten years later in 2015 . The burden is even higher among pregnant women compared to non-pregnant women in both survey years $(p<0.001)$. The burden has remained $57.1 \%$ among pregnant women in 2015 from 58.2\% in 2005 ( $P=0.680)$. This means, there has not be any significant decline of anemia in pregnancy for over 10 years between the surveys (Table 1). Among pregnant women with anemia, a sheer majority had a moderate form in both surveys. There has been a significant decline of severe form of anemia from $2.7 \%$ in 2005 to $1.2 \%$ in 2015 ( $p=0.017)$.

Despite the stagnation of the overall burden of anemia in pregnancy, analysis by region showed changes between regions (Figure 1). A total of 15 regions observed a decline of anemia among pregnant women in Tanzania. The magnitude of change was observed more in Mara (23.2\%), Njombe (16.5\%), Singida (14.7\%), Dodoma (12.4\%), and Rukwa (11.9\%). On the other hand, we noted an increase in the burden of anemia 16 regions and at a various level of change. Regions with a higher increase of anemia included Kigoma (24.1\%), Ruvuma (19.7\%), Kusini Pemba (12.5\%), Kusini Unguja (12.3\%), and Lindi (11.6\%). [see Additional file 1.docx]

\section{Characteristics of anemia among pregnant women in Tanzania}

Table 3 shows the descriptive characteristics of pregnant women in relation to anemia status between the two survey years. The burden of anemia among pregnant women was higher in two age extremes in both surveys. Younger women especially below 20 and older ones above 40 years old had higher burdens 
compared to other age categories. Although not statistically significant, education played a proactive role for anemia. Women with health insurance were more likely having lower burden of anemia. In both surveys, the larger the number of people in the household was related to a higher risk of anemia among pregnant women. Similar was for wealth index-lower risk of anemia among pregnant women living in wealthier households and households with food insecurity.

With regards to reproductive and child characteristics, descriptive analyses suggest that although not significant, the burden of anemia was higher among women who gave birth to their first child at the age of 19 and below. Those with higher number of ANC attendances were less likely to have anemia. Anemia burden was low among those given iron tablets. In both surveys, the burden of anemia was higher among those who gave their previous birth at home compared to health facilities, those who were dewormed, and given antimalaria.

\section{Net change of anemia among pregnant women in Tanzania}

After adjusting for individual, households, reproductive, and child characteristics that seems to have some association with anemia in the general characteristics above, this study found no significant change or decline of anemia among pregnant women in Tanzania between 2005 and 2015, AOR 0.964 , $95 \% \mathrm{Cl}$ (0.774-1.202), $\mathrm{p}=0.747$ (Table 3). In this particular regression analyses, we adjusted for age, highest education level, current marital status, type of residence, number of household members, wealth index, and number of children ever born. In this particular analysis we also adjusted for survey weights.

\section{The current burden of anemia among pregnant women and its determinants in Tanzania}

Over the period of ten survey years (from 2005 to 2015), there has been an improvement in 15 regions while 16 regions in Tanzania mainland and Zanzibar deteriorated [see Additional file 1.docx]. In the most recent survey (2015-2016), anemia among pregnant women was highest in Kaskazini Pemba (81.4\%) followed by Pwani region (79.6\%), Kigoma (77.1\%), Shinyanga (74.5\%). Anemia was the lowest in Njombe region (18\%). Figure 2 shows the burden of anemia as of 2015-2016 national representative survey.

After adjusting for covariates and confounders, there was no difference of the burden of anemia among pregnant women between rural and urban areas in Tanzania (Table 4). Compared pregnant women living in households with up to 3 members, those in bigger size households were more likely to have anemia. For example, compared with households with up to three household members, pregnant women in households with up to six members were 1.3 times more likely to suffer from anemia $(p=0.010)$; in households with up to 9 people were more than 1.5 times more likely to suffer from anemia $(p<0.001)$ and those with more than ten members were more than twice more likely to suffer from anemia $(p<0.001)$. Women in higher than the first and subsequent wealth quintile were less likely to suffer from anemia, though such association did not reach a statistically significant level. 
Anemia was rampart among young pregnant women aged 15-19 years. Pregnant women aged between 20-34 years of age were less likely to succumb anemia compared to young pregnant women aged 15-19 years of age. For example, those between $20-24$ were $24 \%$ less likely to suffer from anemia $(p=0.034)$, those between 25-29 were 33\% less likely to have anemia ( $p=0.010)$, and those between 30-34 were 35\% less likely to suffer from anemia $(p=0.010)$, compared to late teenage pregnant mothers. Although older women were less likely to succumb anemia compared to teenage pregnant mothers, such association did not reach a statistically significant level.

Any level of education among pregnant women in Tanzania was beneficial and protective against anemia in pregnancy compared to no education at all. For example, compared to pregnant women with no education, those with primary education were $31 \%$ less likely to succumb from anemia $(p<0.001)$ and those with secondary school and above education were $26 \%$ less likely to succumb from anemia $(p=0.007)$. Pregnant with previous birth experience were more likely not to have anemia compared to those whose pregnancy was the first. For example, those with three previous pregnancy were $22 \%$ less likely to suffer from anemia compared to those with the current pregnancy $(p=0.044)$.

Food insecurity has a role to play in anemia during pregnancy. Although the association did not reach a statistically significant level, compared to women in food insecure households, those from households with adequate food were $11 \%$ less likely to suffer from anemia $(p=0.052)$. Likewise, those who were covered by some form of health insurance were $30 \%$ less likely to succumb from anemia $(p=0.003)$. Women who were given antimalaria during pregnancy were $12 \%$ less likely to suffer from anemia during pregnancy $(p=0.040)$. Place of delivery during the previous pregnancy seems to have a role in predicting the current pregnancy's anemia. Those who delivered in public health facilities and private health facilities were $26 \%(p=0.013)$ and $36 \%(p<0.001)$ less likely to succumb from anemia in the current pregnancy compared to those who delivered at home. Women who attended ANC clinics in required frequency were $11 \%$ less likely to suffer from anemia in pregnancy $(p=0.050)$.

\section{Discussion}

The burden of anemia did not decline among pregnant women in Tanzania between 2005 and 2015. After those ten years, anemia was more prevalent in pregnant women (57\%) compared women of reproductive age (44\%) in Tanzania mainland and Zanzibar. This unprecedented burden among pregnant women is attributed largely by moderate of anemia contributing up to $30 \%$ of the total burden. In regional comparison, anemia burden has increased in 16 regions while 15 regions of Tanzania observed a modest to significant reduction. Such variation coupled with increment in other regions calls for regional specific and tailored interventions to address anemia. The current burden of anemia among pregnant women in Tanzania is associated with number of household members, woman's age, education level, number of previous children, insurance coverage, use of antimalaria during pregnancy, place of delivery, and frequency of ANC attendance. 
The prevalence of anemia in pregnancy in Tanzania is worrisome. In our previous publications, anemia among other subpopulations varied with regions, but there was a notable decline within the ten years of the surveys (24). In the current analysis too, anemia has exhibited regional differences, however, there a non-significant decline was observed through the ten years of surveys. This is one of the important indirect causes of maternal mortality globally $(1,22)$, and Tanzania is no exception (2). The persistent burden of maternal mortality may as well be explained by persistence of such causes like anemia in pregnancy (27). Addressing anemia and other known causes in this population is therefore an important entry point to attain SDGs.

Anemia in pregnancy may be caused by nutritional inadequacy, particularly on the lack of essential micronutrients such as iron and folic acid $(8,20)$; diseases such as parasitic infestation, particularly hookworms (10); and physiological challenges owing to the growing fetus and its nutritional demands. Owing to the high burden of anemia in the general population (27), majority of women would conceive with already challenged hemoglobin levels (7). Pregnancy at a younger age is a risk factor to maternal challenges including anemia $(11,15)$. Like in other contexts $(19)$, the burden of anemia was higher among the youngest age band of pregnant women and those with demographic disadvantages including lack of or low education attainment. Apart from conception at the younger age, pregnancy at this tender age denies women opportunities to stay in school, accumulate knowledge, skills, and competencies to master life's skills including having better nutrition. Moreover, at this age, they are succumbed to a vicious cycle of poverty and dependency owing low education level, subjecting them to many other demographic disadvantages. This study found association between anemia in pregnancy with age, low education level, and insurance coverage.

A number of interventions are in place to combat anemia in pregnancy and therefore maternal mortality. For example, early antenatal booking is highly recommended to enable expectant mothers are given supplements, preventive therapy with antimalaria, and delivery planning. This study found a clear association between anemia in pregnancy with uptake of antimalaria, frequency attendance to antenatal care, and place of delivery. Such findings are not different from other contexts $(17,18)$, and call for strengthening quality of maternal care, advocating for ANC attendance, and facility delivery.

These analyses showed a difference between regions in Tanzania like in other subpopulations (24). Like in other contexts (8), this can be explained by factors such as food preferences and feeding restrictions that go hand in hand with differences in traditions and customs $(5,23)$; food security $(23)$; agricultural activities, access to and coverage of essential preventive interventions including antenatal services, prevention and treatment of malaria, and iron and folic acid provision (14). Contrary to anemia among underfives in Tanzania (24), women in most of food rich regions have lower magnitude of anemia. Iron is rich in sources of foods that adults consumes in these areas where food is plenty and therefore in favor of their pre-pregnancy and pregnancy iron stores (7). At least 15 regions showed a decline of anemia in the period of ten years, however, 16 others had a worsened anemia burden in the same population. Such regions with increase burden including Kigoma Kigoma, Ruvuma, Tabora, and Lindi, needs targeted 
interventions. This can be achieved through identifying local factors and therefore have impactful solutions.

Evidence from this study should be carefully interpreted owing to the following limitations: we present secular trends over two cycles of DHS data, therefore the participants may not be the same in each survey. Moreover, the newer data set had more variables that could not be comparable with the older one. Such variables included ownership of health insurance, food security, low feeding frequency, and deworming in the last pregnancy. Such variables are important, and, therefore, the inability to compare them poses a limitation to current reporting. Lastly, this was a secondary data analysis in which we could only analyze variables that were present.

\section{Conclusions}

Anemia in pregnancy has not declined over the past ten years despite efforts to address maternal health challenges in Tanzania. Such unprecedented burden remains prevalent among $57 \%$ of pregnant women in the country. The regional variations of the burden of anemia in Tanzania calls for further identification of specific regional determinants and therefore designing tailored interventions. This study found important determinants of anemia including number of household members, woman's age, education level, number of previous children, insurance coverage, use of antimalaria during pregnancy, place of delivery, and frequency of ANC attendance. Addressing such factors and further studies to address further local and regional determinants will help Tanzania attaining the speedy decline the burden of anemia among pregnant women. Of paramount importance, nutrition sensitive interventions such as ensuring girls are well educated and stay in school beyond primary school education, health insurance coverage through social and community insurance schemes, strengthening maternal and child health services through early ANC booking and quality improvement; and nutrition specific interventions such as increasing iron and folic acid supplement coverage early on in pregnancy, prevention of malaria and hookworm infestation, remains crucial.

\section{List Of Abbreviations}

TDHS: Tanzania Demographic and Health Surveys; GIS: Geographic Information System; AOR: Adjusted Odds Ratio; ANC: Antenatal Care; WRA: women of reproductive age; $\mathrm{Hb}$ : hemoglobin; NBS: National Bureau of Statistics; ZBS: Zanzibar Bureau of Statistics; USAID: U.S. Agency for International Development; MEASURE: Monitoring and Evaluation to Assess and Use Results.

\section{Declarations}

Author's Contributions: BS conceptualized the research questions, prepared the analysis plan, revised the analyses; wrote the first draft, and revised the manuscript; YG conducted analyses and revised the manuscript; LM revised the draft manuscript; GL prepared the analysis plan, and revised the manuscript; 
RM revised the manuscript; and $\mathrm{JH}$ conceptualized the research questions, revised the analyses; and revised the manuscript.

Funding: This research was funded by a seed fund provided by the School of Public Health, Fudan University, Shanghai China.

Acknowledgments: We are grateful to the Tanzania National Bureau of Statistics (NBS) and Measure DHS for providing us with the data set and some training on how to download the variables we needed for this analysis.

Competing interests: The authors declare that they have no competing interests.

Availability of data and materials: All datasets are available through request from the DHS website.

Ethics approval and consent to participate: The protocol and data collection procedures for the DHS were approved by NIMR, ZAMREC, the Institutional Review Board of ICF International, and the Centers for Disease Control and Prevention in Atlanta. All participants were asked to provide verbal informed consent after being read a document emphasizing the voluntary nature of the survey. The use of this data was approved by MEASURE DHS after our request with the data analysis protocol. All the data was downloaded from TDHS files.

Patient and Public Involvement statement: Patients or the public were not involved in the design, or conduct, or reporting, or dissemination plans of our research.

Consent for publication: Consent to use and publish articles emanating from this dataset was obtained along with the dataset from the Demographic and Health Survey (DHS) and the National Bureau of Statistics. The data is owned by the ICF International, 530 Gaither Road, Suite 500, Rock-ville, MD 20850.

\section{References}

1. Brabin BJ, Hakimi M, Pelletier D. An analysis of anemia and pregnancy-related maternal mortality. J Nutr. 2001 Feb;131(2S-2):604S-614S; discussion 614S-615S. doi: 10.1093/jn/131.2.604S. PMID: 11160593.

2. Bwana VM, Rumisha SF, Mremi IR, Lyimo EP, Mboera LEG. Patterns and causes of hospital maternal mortality in Tanzania: A 10-year retrospective analysis. PLoS One. 2019 Apr 9;14(4):e0214807. doi: 10.1371/journal.pone.0214807. PMID: 30964909; PMCID: PMC6456219.

3. Chang S, Zeng L, Brouwer ID, Kok FJ, Yan H. Effect of iron deficiency anemia in pregnancy on child mental development in rural China. Pediatrics. 2013 Mar;131(3):e755-63. doi: 10.1542/peds.20113513. Epub 2013 Feb 11. PMID: 23400604.

4. Chu FC, Shen-Wen Shao S, Lo LM, Hsieh TT, Hung TH. Association between maternal anemia at admission for delivery and adverse perinatal outcomes. J Chin Med Assoc. 2020 Apr;83(4):402-407. doi: 10.1097/JCMA.0000000000000215. PMID: 32238782. 
5. Darmawati D, Nizwan-Siregar T, Hajjul K, Tahlil T. Exploring Indonesian mothers' perspectives on anemia during pregnancy: A qualitative approach. Enferm Clin. 2020 Dec 28:S1130-8621(20)305519. English, Spanish. doi: 10.1016/j.enfcli.2020.11.002. Epub ahead of print. PMID: 33384251.

6. Finkelstein JL, Kurpad AV, Bose B, Thomas T, Srinivasan K, Duggan C. Anaemia and iron deficiency in pregnancy and adverse perinatal outcomes in Southern India. Eur J Clin Nutr. 2020 Jan;74(1):112125. doi: 10.1038/s41430-019-0464-3. Epub 2019 Jul 11. PMID: 31296936.

7. Ganatra BR, Hirve SS. Unsafe motherhood: the determinants of maternal mortality. J Indian Med Assoc. 1995 Feb;93(2):47-8. PMID: 7658035.

8. Gibore NS, Ngowi AF, Munyogwa MJ, Ali MM. Dietary Habits Associated with Anemia in Pregnant Women Attending Antenatal Care Services. Curr Dev Nutr. 2020 Dec 11;5(1):nzaa178. doi: 10.1093/cdn/nzaa178. PMID: 33501404; PMCID: PMC7809361.

9. Global, regional, and national trends in haemoglobin concentration and prevalence of total and severe anaemia in children and pregnant and non-pregnant women for 1995-2011: a systematic analysis of population-representative data.

10. Kalinjuma AV, Darling AM, Mugusi FM, Abioye Al, Okumu FO, Aboud S, Masanja H, Hamer DH, Hertzmark E, Fawzi WW. Factors associated with sub-microscopic placental malaria and its association with adverse pregnancy outcomes among HIV-negative women in Dar es Salaam, Tanzania: a cohort study. BMC Infect Dis. 2020 Oct 27;20(1):796. doi: 10.1186/s12879-020-05521-6. PMID: 33109111; PMCID: PMC7590608.

11. Karaçam Z, Kizilca Çakaloz D, Demir R. The impact of adolescent pregnancy on maternal and infant health in Turkey: Systematic review and meta-analysis. J Gynecol Obstet Hum Reprod. 2021 Feb 13:102093. doi: 10.1016/j.jogoh.2021.102093. Epub ahead of print. PMID: 33592347.

12. Kemppinen L, Mattila M, Ekholm E, Pallasmaa N, Törmä A, Varakas L, Mäkikallio K. Gestational iron deficiency anemia is associated with preterm birth, fetal growth restriction, and postpartum infections. J Perinat Med. 2020 Dec 18:jpm-2020-0379. doi: 10.1515/.jpm-2020-0379. Epub ahead of print. PMID: 33554586.

13. Stevens GA, Finucane MM, De-Regil LM, Paciorek CJ, Flaxman SR, Branca F, Peña-Rosas JP, Bhutta ZA, Ezzati M; Nutrition Impact Model Study Group (Anaemia). Global, regional, and national trends in haemoglobin concentration and prevalence of total and severe anaemia in children and pregnant and non-pregnant women for 1995-2011: a systematic analysis of population-representative data. Lancet Glob Health. 2013 Jul;1(1):e16-25. doi: 10.1016/S2214-109X(13)70001-9. Epub 2013 Jun 25. PMID: 25103581; PMCID: PMC4547326.

14. Lyoba WB, Mwakatoga JD, Festo C, Mrema J, Elisaria E. Adherence to Iron-Folic Acid Supplementation and Associated Factors among Pregnant Women in Kasulu Communities in NorthWestern Tanzania. Int J Reprod Med. 2020 Jun 4;2020:3127245. doi: 10.1155/2020/3127245. PMID: 32566646; PMCID: PMC7293754.

15. Massawe SN, Ronquist G, Nyström L, Lindmark G. Iron status and iron deficiency anaemia in adolescents in a Tanzanian suburban area. Gynecol Obstet Invest. 2002;54(3):137-44. doi: 
10.1159/000067879. PMID: 12571434.

16. Meazaw MW, Chojenta C, Muluneh MD, Loxton D. Systematic and meta-analysis of factors associated with preeclampsia and eclampsia in sub-Saharan Africa. PLoS One. 2020 Aug 19;15(8):e0237600. doi: 10.1371/journal.pone.0237600. PMID: 32813750; PMCID: PMC7437916.

17. Nyamu GW, Kihara JH, Oyugi EO, Omballa V, El-Busaidy H, Jeza VT. Prevalence and risk factors associated with asymptomatic Plasmodium falciparum infection and anemia among pregnant women at the first antenatal care visit: A hospital based cross-sectional study in Kwale County, Kenya. PLoS One. 2020 Oct 8;15(10):e0239578. doi: 10.1371/journal.pone.0239578. PMID: 33031456; PMCID: PMC7544053.

18. Rabiu OR, Dada-Adegbola H, Kosoko AM, Falade CO, Arinola OG, Odaibo AB, Ademowo OG. Contributions of malaria, helminths, HIV and iron deficiency to anaemia in pregnant women attending ante-natal clinic in SouthWest Nigeria. Afr Health Sci. 2020 Sep;20(3):1035-1044. doi: 10.4314/ahs.v20i3.6. PMID: 33402949; PMCID: PMC7751510.

19. Rahman MA, Rahman MS, Aziz Rahman M, Szymlek-Gay EA, Uddin R, Islam SMS. Prevalence of and factors associated with anaemia in women of reproductive age in Bangladesh, Maldives and Nepal: Evidence from nationally-representative survey data. PLoS One. 2021 Jan 7;16(1):e0245335. doi: 10.1371/journal.pone.0245335. PMID: 33411804; PMCID: PMC7790421.

20. Schmiegelow C, Msemo OA, Møller SL, Nielsen BB, Paulsen CB, Ødum L, Theander TG, Kavishe RA, Lusingu JPA, Minja DT, Bygbjerg IC. Preconceptional factors associated with haemoglobin concentration in early pregnancy: a community-based cohort study in rural northeastern Tanzania. Trop Med Int Health. 2019 May;24(5):596-607. doi: 10.1111/tmi.13219. Epub 2019 Mar 5. PMID: 30767358.

21. Scholl TO. Iron status during pregnancy: setting the stage for mother and infant. Am J Clin Nutr. 2005 May;81(5):1218S-1222S. doi: 10.1093/ajcn/81.5.1218. PMID: 15883455.

22. Smith C, Teng F, Branch E, Chu S, Joseph KS. Maternal and Perinatal Morbidity and Mortality Associated With Anemia in Pregnancy. Obstet Gynecol. 2019 Dec;134(6):1234-1244. doi: 10.1097/AOG.0000000000003557. PMID: 31764734; PMCID: PMC6882541.

23. Sunguya BF, Poudel KC, Mlunde LB, Urassa DP, Yasuoka J, Jimba M. Poor nutrition status and associated feeding practices among HIV-positive children in a food secure region in Tanzania: a call for tailored nutrition training. PLoS One. 2014 May 20;9(5):e98308. doi:

10.1371/journal.pone.0098308. PMID: 24846016; PMCID: PMC4028312.

24. Sunguya BF, Zhu S, Paulo LS, Ntoga B, Abdallah F, Assey V, Mpembeni R, Huang J. Regional Disparities in the Decline of Anemia and Remaining Challenges among Children in Tanzania: Analyses of the Tanzania Demographic and Health Survey 2004-2015. Int J Environ Res Public Health. 2020 May 17;17(10):3492. doi: 10.3390/ijerph17103492. PMID: 32429508; PMCID: PMC7277528.

25. World Health organization. The global prevalence of anaemia in 2011.Geneva: World Health Organization; 2015 
26. Yadav G, Chambial S, Agrawal N, Gothwal M, Kathuria P, Singh P, Sharma P, Sharma PP. Blood lead levels in antenatal women and its association with iron deficiency anemia and adverse pregnancy outcomes. J Family Med Prim Care. 2020 Jun 30;9(6):3106-3111. doi: 10.4103/jfmpc.jfmpc_78_20. PMID: 32984181; PMCID: PMC7491757.

27. MoHCDGEC Ministry of Health CD, Gender, Elderly and Children - MoHCDGEC/Tanzania Mainland, $\mathrm{MOH}$ Ministry of Health - MoH/Zanzibar, NBS National Bureau of Statistics - NBS/Tanzania, OCGS Office of Chief Government Statistician - OCGS/Zanzibar, Tanzania Demographic and Health Survey and Malaria Indicator Survey 2015 - 2016. Dar es Salaam, Tanzania; 2016.

28. NBS, Macro O. Tanzania Demographic and Health Survey 2004-05. Dar es Salaam, Tanzania; 2005. 29. Sunguya BF, Zhu S, Mpembeni R, Huang J. Trends in prevalence and determinants of stunting in Tanzania: an analysis of Tanzania demographic health surveys (1991-2016). Nutr J. 2019;18(1):85.

\section{Tables}

Table 1: The burden of anemia among women of reproductive age stratified by pregnancy status

\begin{tabular}{|llllll|}
\hline Variable & \multicolumn{2}{l}{$2004-2005$} & \multicolumn{2}{l}{ 2015-2016 } & P-value \\
\cline { 2 - 5 } & $\mathbf{N}$ & $\%$ & $\mathbf{N}$ & $\%$ & \\
\hline Non-pregnant & 4278 & 47.2 & 5218 & 43.7 & 0.009 \\
\hline Pregnant & 625 & 58.2 & 639 & 57.1 & 0.680 \\
\hline Mild & 224 & 22.7 & 283 & 25.3 & 0.230 \\
\hline Moderate & 353 & 32.8 & 342 & 30.6 & 0.383 \\
\hline Severe & 29 & 2.7 & 13 & 1.2 & 0.017 \\
\hline
\end{tabular}

Table 2: Characteristics of pregnant women in relation to the changing burden of anemia among pregnant women in Tanzania 


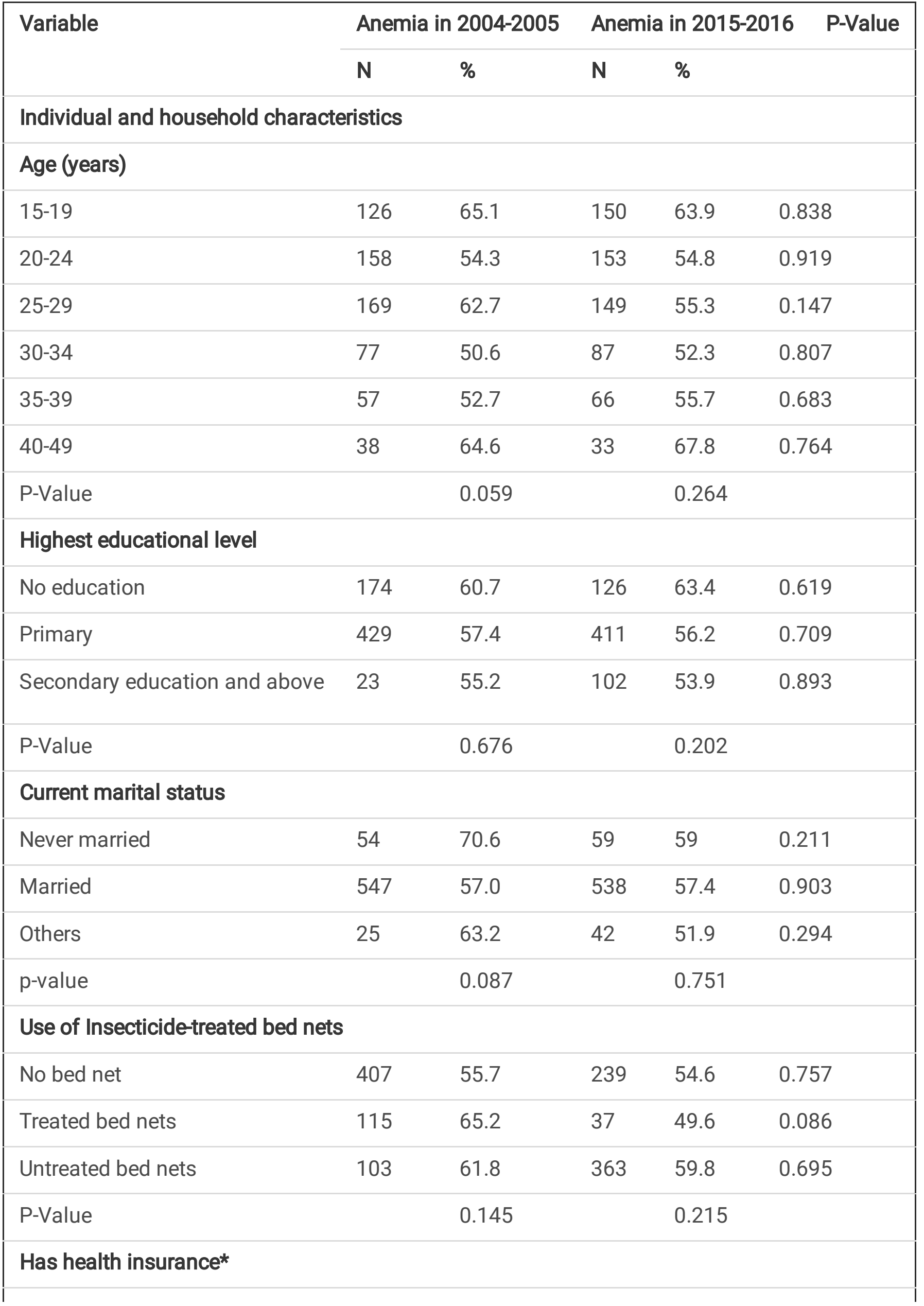




\begin{tabular}{|c|c|c|c|c|c|}
\hline No & & & 604 & 58.1 & \\
\hline Yes & & & 35 & 44.0 & \\
\hline P-Value & & & & 0.040 & \\
\hline Type of $r$ & & & & & \\
\hline Urban & 119 & 57.3 & 176 & 53.6 & 0.506 \\
\hline Rural & 506 & 58.4 & 463 & 58.6 & 0.960 \\
\hline P-Value & & 0.828 & & 0.187 & \\
\hline Number & & & & & \\
\hline $1-3$ & 160 & 52.4 & 146 & 51.5 & 0.851 \\
\hline $4-6$ & 233 & 57.3 & 231 & 53.1 & 0.299 \\
\hline $7-9$ & 130 & 61.4 & 146 & 63.1 & 0.757 \\
\hline $10+$ & 102 & 67.9 & 116 & 68.9 & 0.867 \\
\hline P-Value & & 0.032 & & 0.005 & \\
\hline Wealth in & & & & & \\
\hline Poorest & 139 & 59.4 & 153 & 57.9 & 0.761 \\
\hline Poorer & 136 & 57.4 & 137 & 58.1 & 0.901 \\
\hline Middle & 136 & 65.2 & 127 & 63.0 & 0.690 \\
\hline Richer & 111 & 51.0 & 119 & 56.1 & 0.441 \\
\hline Richest & 103 & 58.3 & 103 & 50.2 & 0.213 \\
\hline P-Value & & 0.281 & & 0.285 & \\
\hline Food sec & & & & & \\
\hline Insecure & & & 290 & 60.9 & \\
\hline Secure & & & 349 & 54.3 & \\
\hline P-Value & & & & 0.077 & \\
\hline Low Feec & & & & & \\
\hline No & & & 431 & 58.0 & \\
\hline Yes & & & 208 & 55.4 & \\
\hline P-Value & & & & 0.429 & \\
\hline
\end{tabular}




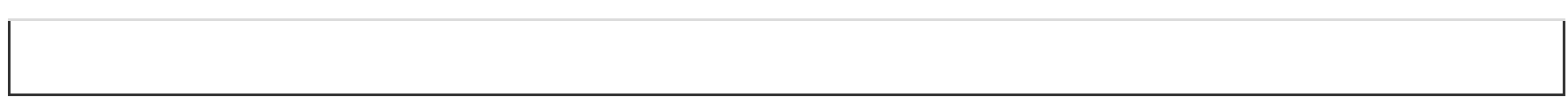

Maternal characteristics 


\begin{tabular}{|c|c|c|c|c|c|}
\hline \multicolumn{6}{|c|}{ Number of children ever born } \\
\hline 0 & 136 & 63.3 & 170 & 60.8 & 0.658 \\
\hline 1 & 115 & 53.9 & 126 & 55.5 & 0.787 \\
\hline 2 & 118 & 61.5 & 95 & 48.4 & 0.025 \\
\hline 3 & 60 & 52.4 & 70 & 53.6 & 0.881 \\
\hline $4+$ & 197 & 57.7 & 178 & 62.4 & 0.346 \\
\hline P-Value & & 0.342 & & 0.088 & \\
\hline \multicolumn{6}{|c|}{ Age at the first childbirth (years) } \\
\hline 0-19 & 338 & 57.7 & 310 & 58.0 & 0.939 \\
\hline $20-49$ & 152 & 55.3 & 158 & 52.1 & 0.515 \\
\hline P-Value & & 0.559 & & 0.182 & \\
\hline \multicolumn{6}{|c|}{ Gestation age at ANC booking } \\
\hline $0-3$ & 36 & 54.5 & 74 & 57.4 & 0.725 \\
\hline $4-6$ & 341 & 57.6 & 283 & 57.5 & 0.964 \\
\hline $7-9$ & 45 & 58.1 & 33 & 57.5 & 0.954 \\
\hline P-Value & & 0.887 & & 1.000 & \\
\hline \multicolumn{6}{|l|}{ Number of ANC visit } \\
\hline $0-3$ & 177 & 62.3 & 234 & 61.7 & 0.903 \\
\hline 4 and above & 254 & 54.2 & 167 & 53.4 & 0.859 \\
\hline P-Value & & 0.072 & & 0.060 & \\
\hline \multicolumn{6}{|l|}{ Provision of IFA } \\
\hline No & 178 & 60.7 & 98 & 61.2 & 0.940 \\
\hline Yes & 253 & 55.0 & 304 & 57.1 & 0.573 \\
\hline P-Value & & 0.199 & & 0.456 & \\
\hline \multicolumn{6}{|l|}{ Place of delivery } \\
\hline At home & 250 & 58.8 & 188 & 63.5 & 0.272 \\
\hline Public health facility & 154 & 56.9 & 179 & 54.8 & 0.663 \\
\hline Private health facility & 31 & 50.3 & 28 & 46.6 & 0.736 \\
\hline P-Value & & 0.592 & & 0.048 & \\
\hline
\end{tabular}




\begin{tabular}{|llllll|}
\hline Deworming * & & & & & \\
No & & & 161 & 61.5 & \\
Yes & & & 240 & 56.0 & \\
P-Value & & & & 0.220 & \\
Antimalaria given & & & & & \\
No & 292 & 57.6 & 149 & 63.0 & 0.196 \\
Yes & 138 & 56.9 & 251 & 55.4 & 0.740 \\
P-Value & & 0.863 & & 0.075 & \\
\hline
\end{tabular}

*: Data was available for only one dataset

Table 3. Anemia in pregnancy in TDHS 2015-2016 compared to TDHS 2004-2005

\begin{tabular}{|llll|}
\hline Variable & AOR & $95 \% \mathrm{Cl}$ & P-Value \\
\hline Survey year & & & \\
\hline $2004-2005$ & Ref & & \\
\hline $2015-2016$ & 0.964 & $0.774-1.202$ & 0.747 \\
\hline
\end{tabular}

Table 4. Remaining factors associated with anemia in pregnancy, TDHS 2015-2016 


\begin{tabular}{|c|c|c|c|}
\hline Variable & AOR & $95 \% \mathrm{Cl}$ & $p$-Value \\
\hline \multicolumn{4}{|c|}{ Household characteristics } \\
\hline \multicolumn{4}{|c|}{ Type of residence } \\
\hline urban & 1.000 & & \\
\hline rural & 1.071 & $0.902-1.271$ & 0.432 \\
\hline \multicolumn{4}{|c|}{ Number of household members } \\
\hline $1-3$ & 1.000 & & \\
\hline $4-6$ & $1.285^{\star \star}$ & $1.054-1.566$ & 0.013 \\
\hline $7-9$ & 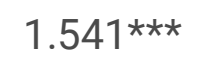 & $1.241-1.913$ & 0.000 \\
\hline $10+$ & 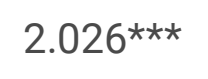 & $1.603-2.560$ & 0.000 \\
\hline \multicolumn{4}{|l|}{ Wealth index } \\
\hline poorest & 1.000 & & \\
\hline poorer & 1.080 & $0.899-1.298$ & 0.410 \\
\hline middle & 1.045 & $0.868-1.259$ & 0.640 \\
\hline richer & 1.122 & $0.922-1.367$ & 0.250 \\
\hline richest & 1.198 & $0.931-1.542$ & 0.160 \\
\hline \multicolumn{4}{|c|}{ Individual Characteristics } \\
\hline \multicolumn{4}{|l|}{ Age } \\
\hline $15-19$ & 1.000 & & \\
\hline $20-24$ & $0.762^{\star \star}$ & $0.592-0.979$ & 0.034 \\
\hline $25-29$ & $0.678^{\star \star}$ & $0.505-0.912$ & 0.010 \\
\hline $30-34$ & $0.646 * \star \star$ & $0.464-0.901$ & 0.010 \\
\hline $35-39$ & 0.799 & $0.561-1.138$ & 0.214 \\
\hline $40-49$ & 0.764 & $0.527-1.108$ & 0.156 \\
\hline \multicolumn{4}{|c|}{ Highest educational level } \\
\hline no education & 1.000 & & \\
\hline primary & $0.691 * \star \star$ & $0.590-0.808$ & 0.000 \\
\hline
\end{tabular}




\begin{tabular}{|c|c|c|c|}
\hline Secondary education and above & $0.742^{\star \star *}$ & $0.597-0.923$ & 0.007 \\
\hline \multicolumn{4}{|l|}{ Current marital status } \\
\hline never married & 1.000 & & \\
\hline married & 1.172 & $0.909-1.510$ & 0.221 \\
\hline other & 1.124 & $0.839-1.505$ & 0.434 \\
\hline \multicolumn{4}{|l|}{ Number of children ever born } \\
\hline 1 & 1.000 & & \\
\hline 2 & 0.942 & $0.769-1.155$ & 0.567 \\
\hline 3 & $0.778 * \star$ & $0.609-0.993$ & 0.044 \\
\hline $4+$ & 0.819 & $0.627-1.070$ & 0.143 \\
\hline \multicolumn{4}{|l|}{ Food Security } \\
\hline Insecure & 1.000 & & \\
\hline Secure & $0.887^{*}$ & $0.785-1.001$ & 0.052 \\
\hline \multicolumn{4}{|l|}{ Low Feeding Frequency } \\
\hline No & 1.000 & & \\
\hline Yes & 1.006 & $0.886-1.142$ & 0.930 \\
\hline \multicolumn{4}{|l|}{ Covered by health insurance } \\
\hline No & 1.000 & & \\
\hline Yes & $0.701^{\star \star \star}$ & $0.556-0.883$ & 0.003 \\
\hline \multicolumn{4}{|l|}{ Antimalaria given } \\
\hline No & 1.000 & & \\
\hline Yes & $0.877^{\star \star}$ & $0.775-0.994$ & 0.040 \\
\hline \multicolumn{4}{|l|}{ Place of delivery } \\
\hline At home & 1.000 & & \\
\hline Public health facility & $0.840^{\star *}$ & $0.733-0.963$ & 0.013 \\
\hline Private health facility & $0.639 * \star \star$ & $0.520-0.786$ & 0.000 \\
\hline \multicolumn{4}{|l|}{ Number of ANC visit } \\
\hline $0-3$ & 1.000 & & \\
\hline
\end{tabular}




\begin{tabular}{|llll|}
\hline 4 and above & $0.889 *$ & $0.791-1.000$ & 0.050 \\
\hline Age at the first childbirth (years) & & & \\
\hline $0-19$ & 1.000 & & \\
\hline $20-49$ & 1.032 & $0.900-1.184$ & 0.652 \\
\hline
\end{tabular}

Note: Logistic regression with household-level random intercepts was used. Survey weights were also adjusted.

\section{Figures}

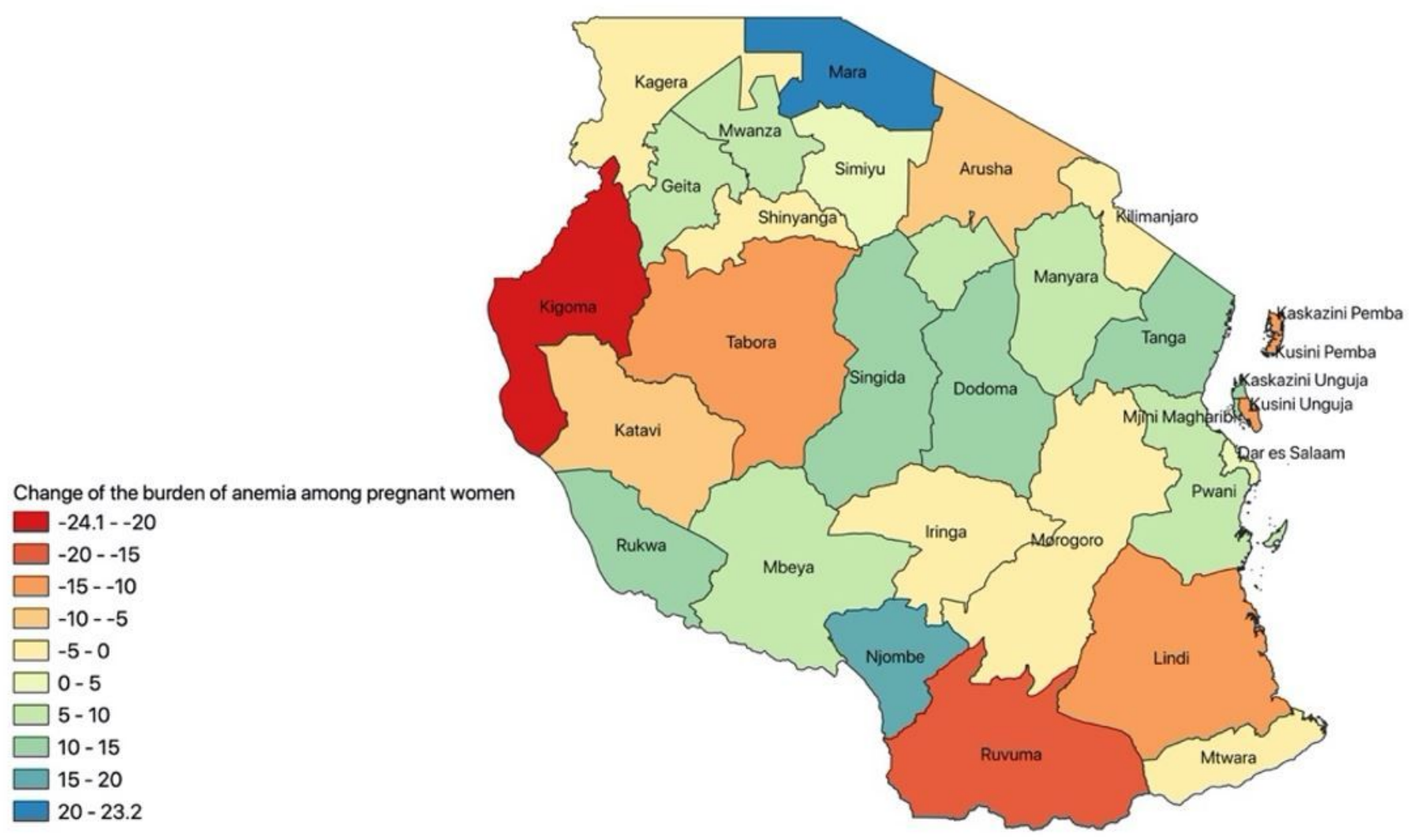

Figure 1

GIS Mapping showing changes in the burden of anemia among pregnant women between 2005 and 2015 Note: The designations employed and the presentation of the material on this map do not imply the expression of any opinion whatsoever on the part of Research Square concerning the legal status of any country, territory, city or area or of its authorities, or concerning the delimitation of its frontiers or boundaries. This map has been provided by the authors. 

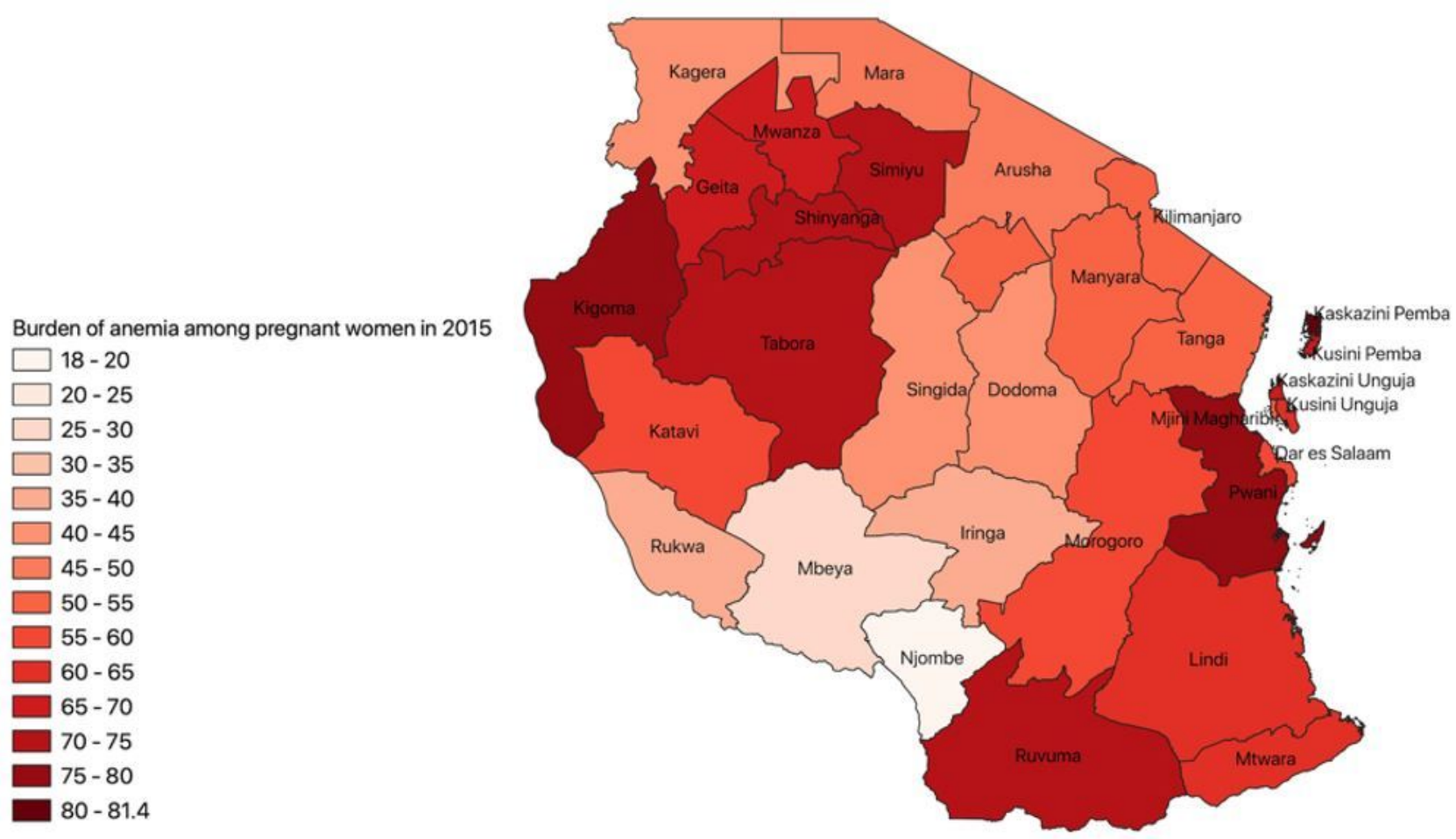

Figure 2

The GIS mapping of the regional burdens of anemia among pregnant in 2015-2016 survey Note: The designations employed and the presentation of the material on this map do not imply the expression of any opinion whatsoever on the part of Research Square concerning the legal status of any country, territory, city or area or of its authorities, or concerning the delimitation of its frontiers or boundaries. This map has been provided by the authors.

\section{Supplementary Files}

This is a list of supplementary files associated with this preprint. Click to download.

- Additionalfile1.docx 